\title{
The Impact of Human Resource Information System on Strategic Decisions in Iran
}

\author{
Hassan Rangriz (Ph.D) \\ Assistant Professor, Department of Management, School of Economic Sciences \\ No. 66, Roudsar Ave, Hafez Ave, P. O. Box: 15875-1111, Tehran, Iran \\ Tel: 98-912-226-2026 E-mail: hassanrangriz@yahoo.com \\ Javad Mehrabi (Ph.D) \\ Assistant Professor, Faculty of Management \& Accounting, Islamic Azad University \\ Qazvin Branch, No. 1, Daneshgah Ave, P. O. Box: 34185- 1416, Qazvin, Iran \\ Tel: 98-281-3675-787Ｅ-mail: mehrabijavad@yahoo.com
}

Alireza Azadegan (M.A.)
Researcher, Tehran, Iran

Tel: 98-912-8158675Ｅ-mail: Azadegan1981@yahoo.com

\begin{abstract}
Purpose - The purpose of this paper is to examine the impact of Human resource information system (HRIS) on strategic decisions.

Design/methodology/approach - The papers develops a research model based on current literature and then test this model in Mellat and Parsian banks selected from 19 banks with 18000 branches, public and private sectors in Iran. Statistics society consists of 172 persons include assistant of general managers in both personnel affairs and welfare and domestic payments department in Mellat bank, and also professionals, managers and deputy of personnel affair and department of organisation and methods in Parsian bank. The sample size provided based on "Cohan- Morgan- Korjsay" is 108 persons which has been determined with descriptive methods. For data analyzing we used Chi- square test, Binomial test, and Kendall's tau- $\mathrm{b}$ test.
\end{abstract}

Findings - The results indicate that, on average, few differences exist between Mellat and Parsian banks. Moreover, we found that the HRIS is effective on strategic decisions in both banks.

Research limitations/implications - This study could benefit from a large sample, from public and private banks and replication in more branches.

Practical implications - The paper offers practical suggestions to the banking industry and management in general on how to manage the HRIS effects on strategic decisions.

Originality/value - This paper has tried to provide an inclusive understanding about the HRIS effects on strategic decisions in the banking industry. Since there was a lack of such research in an Iranian context, this paper can provide theoretical basis for future researches as well as practical implications for managers and the human resource (HR) professionals.

Keywords: Human resource information system, Strategic decisions, Banking

\section{Introduction}

The main objectives of this paper are to identify the major variables affecting of the HRIS within the Iran banking industry (IBI) and to examine the impact of HRIS on strategic decisions. While there have been several studies in different industries in related to information system (IS), a few of them are within the IBI. Also, although the survival of a range of involvement systems used by professionals from various industries, little research has been undertaken to examine if these interventions can be applied to the IBI. There are therefore two gaps in management information system (MIS). First, there is a lack of study in HRIS, particularly in Iran, framework. Second, the past studies have paying attention on IS. This study had the aim of overcoming these two gaps to achieve the objectives 
stated at the start of this paper. Thus, the motivation for this paper is to address the identified the core factors by reporting on the impact of HRIS on strategic decisions among HR professionals within the IBI. These findings have an implication for HR professionals within the IBI.

The paper is structured as follows: first, a general literature review on the HRIS and strategic decisions in various industries is presented, with the main focus on the key concepts HRIS and strategic decisions; second, a brief overview of the advocated theoretical conceptual framework which summaries the relationship among the independent variables (HRIS) and dependent variables (strategic decisions) is presented. This is followed by an explanation of the research methodology adopted. Following on from the research methods, the statistical methods employed and the interpretation of the findings are next, the focus of which is to compares HRIS in both banks. The paper concludes with a discussion and implications for future research.

\section{Research Objectives}

This study explores the role of HRIS in strategic decisions in IBI. The question to address in this study therefore is "What role if any do HRIS play in strategic decisions in Mellat and Parsian banks?"

\section{Literature Review}

Invariably, human resource management (HRM) issues have been major concern for managers at all levels, because they all meet their goals through the efforts of others, which require the effective and efficient management of people (Dessler et al., 1999).The spacious array of HRM activities for example, planning, recruiting, selection, and training just to mention but few place enormous responsibilities on supervisors and managers alike. These embrace analyzing jobs, planning labour needs, selecting employees, orienting and training employees, managing compensation, communicating (which includes counseling and disciplining), and maintaining employee commitment. In addition to the already mentioned activities are, ensuring fair treatment, appraising performance, ensuring employee health and safety, building and maintaining good employee/labour relations; handling complains and grievances, and ensuring compliance with human rights, occupational health and safety, labour relations, and other legislation affecting the workplace. Regardless of field of expertise, from accounting to production control, learning about employee rights, employer responsibilities, and effective HRM practices may provide all managers with knowledge that enables them to perform more effectively.

However, according to Stewart (1996), the HRM function has faced a scuffle in justifying its position in organisations. Firms easily justify expenditures on training, staffing, reward, and employee involvement systems in favorable conditions, but when faced with financial difficulties, such HR systems become prime target for cutbacks. Nonetheless, introducing strategic human resource management (SHRM), in exploring HR's supportive role in business strategy, presented a possibility for demonstrating its value to the firm. Consequently, Walker (1978) called for a connection between strategic planning and HR planning marking the commencement of the field of SHRM, but it was not until early 1980s before extensive work was carried out on this proposed linkage. For instance, a comprehensive study by Devanna, Fombrum and Tichy (1984) was devoted to exploring the link between business strategy and HR. Since then, SHRM's evolution has consistently been followed by a few years of developments within the field of strategic management. A very good example is Miles and Snow's (1978) organisational types that were later expanded to include their associated HR systems (Miles and Snow, 1984). SHRM researchers used Porter's (1980) model of generic strategies later to explain the specific HR strategies that one would expect to observe under each of them (Jackson and Schuler, 1987; Wright and Snell, 1991).

Lately, the increasing pressure to support strategic objectives and the greater focus on shareholder value have led to changes in both job content and expectations of HR professionals (Storey et al., 2000; Ball, 2000). Similarly, Schuler et al., (2001) and Mayfield et al., (2003) noted that one such major changes included contemporary use of IS in support of the HRM process. More so, a careful analysis indicated that increased HRIS usage enabled improved professional performance and thus facilitated involvement in internal consultancy activities. In addition, according to Ulrich (1997), using HRIS provides value to the organisation and improves HR professionals' own standing in the organisation. In another development, Brockbank (1999) suggested the need for HR to become a strategic partner.

HRIS provides management with strategic data not only in recruitment and retention strategies, but also in merging HRIS data into large-scale corporate strategy. The data collected from HRIS provides management with decision-making tool. Through proper HRM, firms are able to perform calculations that have effects on the business as a whole. Such calculations include health-care costs per employee, pay benefits as a percentage of operating expense, cost per hire, return on training, turnover rates and costs, time required to fill certain jobs, return on human capital invested, and human value added. It must be noted though, that, none of these 
calculations result in cost reduction in the HR function (Gerardine DeSanctis, 1986). The aforementioned areas however, may realize significant savings using more complete and current data made available to the appropriate decision makers. Consequently, HRIS are seen to facilitate the provision of quality information to management for informed decision-making. Most notably, it supports the provision of executive reports and summaries for senior management and is crucial for learning organisations that see their human resource as providing a major competitive advantage. HRIS is therefore a medium that helps HR professionals perform their job roles more effectively (Grallagher, 1986; Broderick and Boudreau, 1992).

Further, various studies had offered a conclusive evidence to affirm the role HRIS plays in support of strategic decision-making. There has been a dramatic increase in HRIS's usage. For example, Lawler and Mohrman (2003)in Agyenim Boateng (2007) and in Hussain et al., (2006) established that the use of HRIS had consistently increased over the previous years, irrespective of the degree of strategic partnership held by the HR function. Definitely, HRIS usage had increased substantially even in firms where HR had no strategic role. They cautioned, however, that HRIS usage and, in particular, fully integrated HRIS systems, did not necessarily ensure that HR would become a full strategic partner. Even though, numerous studies in this area have provided substantial empirical and theoretical contributions to the field of HRIS this area of investigation is still in its infancy. Interestingly, little however is known about the role of HRIS in SHRM. As the pressure to shift from HRM to SHRM keeps on mounting, coupling with severe global competition, and in conjunction with the ever-increasing demand for HRIS, further research is still needed in this field.

\section{Proposed Research Model}

Studies have shown the impact of HRIS on strategic decisions. Strategic decisions are related to the strategic nature of HRM. According to Michal Armstrong (2008) the most significant feature of HRM is the importance attached to strategic integration, which flows from top management's vision and leadership, and which requires the full commitment of people to it. David Guest $(1987,1989 a, 1989 b, 1991)$ believes that this is a key policy goal for HRM, which is concerned with the ability of the organisation to integrate HRM issues into its strategic plans, to ensure that the various aspects of HRM cohere, and to encourage line managers to incorporate an HRM perspective into their decision making. Karen Legge (1989) considers that one of the common themes of the typical definitions of HRM is that HR policies should be integrated with strategic business planning. Keith Sisson (1990) suggests that a feature increasingly associated with HRM is a stress on the integration of HR policies both with one another and with business planning more generally. John Storey (1989) suggests that 'The concept locates HRIS policy formulation firmly at the strategic level and insists that a characteristic of HRM is its internally coherent approach.' Therefore, HRIS can be conceptualized as collateral for developing strategic decisions within organisations. In the section that follows we make effort to integrate HRIS, and strategic decisions based on figure No. 1 that shows our proposed research model.

Therefore, the hypotheses are that:

H1. HRIS are used by HR professionals in support of strategic tasks.

H2. HRIS will be used differentially by Mellat and Parsian banks in support of strategic decision making in the future.

H3. HRIS will be used more in support of strategic decision making in banks in the future.

H4. HRIS are used differentially by Mellat bank in support of strategic decision making relative to Parsian bank.

H5. HRIS are seen as an enabling technology by HR professionals.

H6. HRIS usage for strategic decision making leads to enhanced professional standing.

\section{Methodology}

\subsection{Purpose}

This research is designed to investigate the impact of HRIS on strategic decisions in IBI. No studies currently exist on the impact of HRIS on strategic decisions in IBI. The results of this study should help Iranian managers determine whether tight HR should be expended on HRIS and strategic decisions programs or if the finding could be better utilized elsewhere within the IBI.

\subsection{Sample and Data Collection}

All of the IBI involved in the study are located in Tehran which is one of large province in Iran and plays a vital role in the social/economic development of the country. A list of all IBI was compiled from the following 
sources: personnel affairs and welfare and domestic payments department, deputy of personnel affair, and department of organisation and methods.

A questionnaire was used to collect the data. It included closed questions and was organized into seven sections. Section one consisted of 4 questions concerning responder demographics. Section two focused on information about usage of HRIS by HR professionals in support of strategic tasks. Section three focused on information about usage of HRIS difference forms in both banks in support of strategic decision making in future. Section four dealt with information about usage of HRIS in both banks in support of strategic decision making in the future. Section five focused on information about usage of HRIS difference forms in both banks in support of strategic decision making at now. Section six focused on information about HRIS as an enabling technology by HR professionals. Section seven focused on information about usage of HRIS for strategic decision making that leads to enhanced professional standing. The sample size provided based on "Cohan- Morgan- Korjsay" is 108 persons which has been determined with descriptive methods. For data analyzing we used Chi- square test, Binomial test, and Kendall's tau- $\mathrm{b}$ test.

\subsection{Validity and Reliability}

This research is designed to investigate the impact of HRIS on strategic decisions in Mellat and Parsian banks. A quantitative research methodology was applied in the study, specifically to assist in finding answers to the research question. After an examination of the literature and the empirically tested questionnaire available to the researchers, the Z. Hussain et al. (2006) questionnaire for HRIS was chosen for use in this research. Z. Hussain et al. (2006) showed that HRIS measures were more valid than pointed out in prior research. The Cronbach's alpha for this scale was 0.71 .

\section{Analysis and Results}

\section{Hypothesis 1:}

H0. HRIS aren't used by HR professionals in support of strategic tasks.

H1. HRIS are used by HR professionals in support of strategic tasks.

Data for this hypothesis were obtained from responses to survey question 5. "At which level can HRIS support you in your emerging roles, such as HR consultancy and strategic decision making?" The suitability of the response was gauged by qualifying questions 1,6 , and 7 . Chi- square test for HRIS use by HR professionals was conducted to assess whether the amount of users to non- users differed between Mellat and Parsian banks.

As calculated amounts for significant level of Pearson Chi. Square (Sig. $=.038$ ) have expected count less than $\% 5$, so in the level of $\alpha=0.05$, the hypothesis (H1) is confirmed. In which by 95 percent of confidence, there is strong evidence that HRIS were used in support of strategic tasks.

\section{Hypothesis 2:}

Ho. HRIS will not be used differentially by Mellat and Parsian banks in support of strategic decision making in the future.

H1. HRIS will be used differentially by Mellat and Parsian banks in support of strategic decision making in the future.

Data for this hypothesis were obtained from responses to survey question 11. "What strategic HR tasks are you performing that are supported by HRIS?" The suitability of the response was gauged by qualifying questions 3, and 6. Chi- square test for HRIS use by HR professionals was conducted to assess whether the amount of users to non- users differed between Mellat and Parsian banks.

As calculated amounts for significant level of Pearson Chi. Square $($ Sig. $=.704)$ have expected count more than $\% 5$, so in the level of $\alpha=0.05$, the hypothesis (H1) is not confirmed. In which by 95 percent of confidence, the overall use of HRIS in support of strategic decision making in future was highly consistent for Mellat and Parsian banks.

\section{Hypothesis 3:}

H0. HRIS will not be used more in support of strategic decision making in banks in the future.

H1. HRIS will be used more in support of strategic decision making in banks in the future.

Data for this hypothesis were obtained from responses to survey question 9. "What is your view of development of HRIS in your bank for work and decision making?" The suitability of the response was gauged by qualifying question 6. A binomial test was performed to see whether HR professionals will use HRIS more in support of 
strategic decision making in the future. Two separate binomial tests also undertaken for each of the tasks grouping in our study.

As calculated amounts for Asymp. Sig. (2- tailed) have count less than \%5, so in the level of $\alpha=0.05$, the hypothesis (H1) is confirmed. In which by 95 percent of confidence, there is strong evidence that HRIS will be used more in support of strategic decision making for Mellat and Parsian banks in future.

\section{Hypothesis 4:}

H0. HRIS aren't used differentially by Mellat bank in support of strategic decision making relative to Parsian bank.

H1. HRIS are used differentially by Mellat bank in support of strategic decision making relative to Parsian bank.

Data for this hypothesis were obtained from responses to survey question 12. "If you are now using HRIS in support of strategic decision making, what is your role?" The suitability of the response was gauged by qualifying question 6. Chi- square test was conducted to assess whether the amount of users to non- users differed between Mellat and Parsian banks in present.

As calculated amounts for significant level of Pearson Chi. Square $($ Sig. $=.612)$ have expected count more than $\% 5$, so in the level of $\alpha=0.05$, the hypothesis (H1) is not confirmed. In which by 95 percent of confidence, the Mellat and Parsian banks do not use HRIS for strategic decision making present differently. On the other hand, the relative use of HRIS by both banks for information provision in strategic decision making was similar.

\section{Hypothesis 5:}

H0. HRIS are not seen as an enabling technology by HR professionals.

H1. HRIS are seen as an enabling technology by HR professionals.

Data for this hypothesis were obtained from responses to survey question 2. "At which level can HRIS support you in your normal HRM duties?" The suitability of the response was gauged by qualifying questions 6,8 , and 10 . Here enabling technology was seen as supporting advanced tasks. Chi- square test for HRIS used by HR professionals was conducted to assess whether the amount of users to non- users are seen as an enabling technology.

As calculated amounts for significant level of Pearson Chi. Square (Sig. $=.017)$ have expected count less than $\% 5$, so in the level of $\alpha=0.05$, the hypothesis (H1) is confirmed. In which by 95 percent of confidence, HRIS were seen as a crucial and enabling technology by HR professionals.

\section{Hypothesis 6:}

H0. HRIS usage for strategic decision making doesn't lead to enhanced professional standing.

H1. HRIS usage for strategic decision making leads to enhanced professional standing.

Data for this hypothesis were obtained from responses to survey questions 13, and 14. "At which level can HRIS support you in your normal HRM duties?" The suitability of the response was gauged by qualifying questions 4, and 6. To confirm that there was consistency between the responses for self- assessed enhancement and perceived acceptance of enhanced status by the bank. We obtained a measure of correlation between the two responses. To take ties into account, Kendall's tau- $\mathrm{b}$ coefficient was calculated. We considered that those who were not currently using HRIS for strategic decision making, and responded as neutral when assessing enhancement of professionals standing, did so due to a lack of practical exposure. This category was therefore excluded and the overall responses for self- assessment, perceived organisational recognition and potential enhancement were assessed individually using binomial test.

As calculated amounts for Kendall's tau-b $(\mathrm{T}=.595)$ with significant level have count less than $\% 5$, so in the level of $\alpha=0.05$, the hypothesis (H1) is confirmed. In which by 95 percent of confidence, there was very strong evidence that those using HRIS for strategic partnering role enhanced their standing.

\section{Conclusions}

This study investigated the apparent effect of HRIS on strategic decisions in IBI. The analysis of research results showed the overall consistency of findings with the model. This study makes two key contributions to the literature. First, this study reveals how banks can usage the HRIS in strategic decisions. Specifically, the findings of the study show the key role of HRIS in the strategic tasks. The study's theoretical arguments and its empirical findings are both interesting and useful to scholars in this research area. Second, this paper shows theoretically and empirically how banks can generate business value from IS-enabled culture, a topic that has received little 
attention to date. The findings on this topic are thus also valuable for academics who study the business value of HRIS.

\section{Limitations}

Some limitations of the research need to be recognized. The sample is relatively small (108), comparable to others studies that have looked at the mangers level within the banking industry within the Iranian context, as such it is representative and the findings presented are general to a wider population of banks in the IBI.

\section{Future Research}

This study confirms the applicability of HR professionals related issues in developing countries such as Iran. Owing to this, there is a possibility of bias playing role in the outcome of the study. Therefore, this study can be emphasized in other banks particularly the public and private banks within the Iranian context. One major implication emerging from this study is the challenge of finding ways of valuing contributions of the banking industry.

\section{References}

Armstrong, M. (2008). Strategic Human Resource Management: A Guide to Action, Kogan Page, London.

Ball, K. (2000). The use of Human Resource Management Systems: A Survey, Personnel Review, 30 (6), pp. 667-693.

Broderick, R., Boudreau, W. (1992). Human Resource Management, Information Technology Executive, 6 (2), pp. 7- 17.

Dessler G., Cole Nina D., \& Sutherland Virginia L. (1999). Human Resources Management In Canada seventh edition. Prentice-Hall Canada Inc. Scarborough, Ontario.

Devanna M. A., Fombrun C. J., \& Tichy N. M. (1984). Strategic Human Resource Management, Wiley, New York.

Gallagher, M. (1986), Computers in Personnel Management, Heinemann, UK.

Gerardine D. (1986). Human Resource Information Systems- A Current Assessment, MIS Quarterly, Vol. 10, No.1, pp. 15-27.

Guest, D E (1987). Human resource management and industrial relations, Journal of Management Studies, 14 (5), pp 503-21.

Guest, D E. (1989a). Human resource management: its implications for industrial relations and trade unions, in New Perspectives in Human Resource Management, ed. J Storey, Routledge, London.

Guest, D E. (1989b). Personnel and HRM: can you tell the difference?, Personnel Management, January, pp $48-51$.

Guest, D E. (1991). Personnel management: the end of orthodoxy, British Journal of Industrial Relations, 29 (2), pp 149-76.

Hussain, Z., Wallace, J., \& Cornelius, N. E. (2006). The Use and Impact of Human Resource Information Systems on Human Resource Management Professionals, Information \& Management, 44, pp. 74-89.

Jackson, S., Schuler, R.S. (1987). Linking Competitive Strategies and Human Resource Management Practices, Academy of Management Executive, 1(3), pp. 209-213.

Lawler, E. E., Mohrman, S. A. (2003). Human Resource as a Strategic Partner: What does it take to make it happen? Human Resource Planning, 26 (3), pp. 15- 29.

Legge, K. (1989). Human resource management: a critical analysis, in New Perspectives in Human Resource Management, ed. J Storey, Routledge, London.

Mayfield, J., Mayfield, J., Lunce, S. (2003). Human Resource Information Systems: A Review and Model Development, Advances in Competitiveness Research, 11, pp. 139- 151.

Porter, M.E. (1980). What is a Strategy, Harvard Business Review, Nov. Dec. pp.61-78.

Schuler, R. S., Jackson, S. E., Storey, J. J. (2001). Human Resource Management and its Link with Strategic Management, in: J. Storey (ed.), Human Resource Management: A critical Text, Second ed., Thomson Learning, London. 
Sisson, K. (1990). Introducing the Human Resource Management Journal, Human Resource Management Journal, 1 (1), pp 1-11.

Storey, J. (1989). From personnel management to human resource management, in New Perspectives on Human Resource Management, ed. J Storey, Routledge, London.

Ulrich, D. (1997). Human Resource Champions: The Next Agenda for Adding Value to Human Resource Practices, Harvard Business School Press, Boston.

Walker, A. J., (1978). Web-Based Human Resources, McGraw Hill, New York.

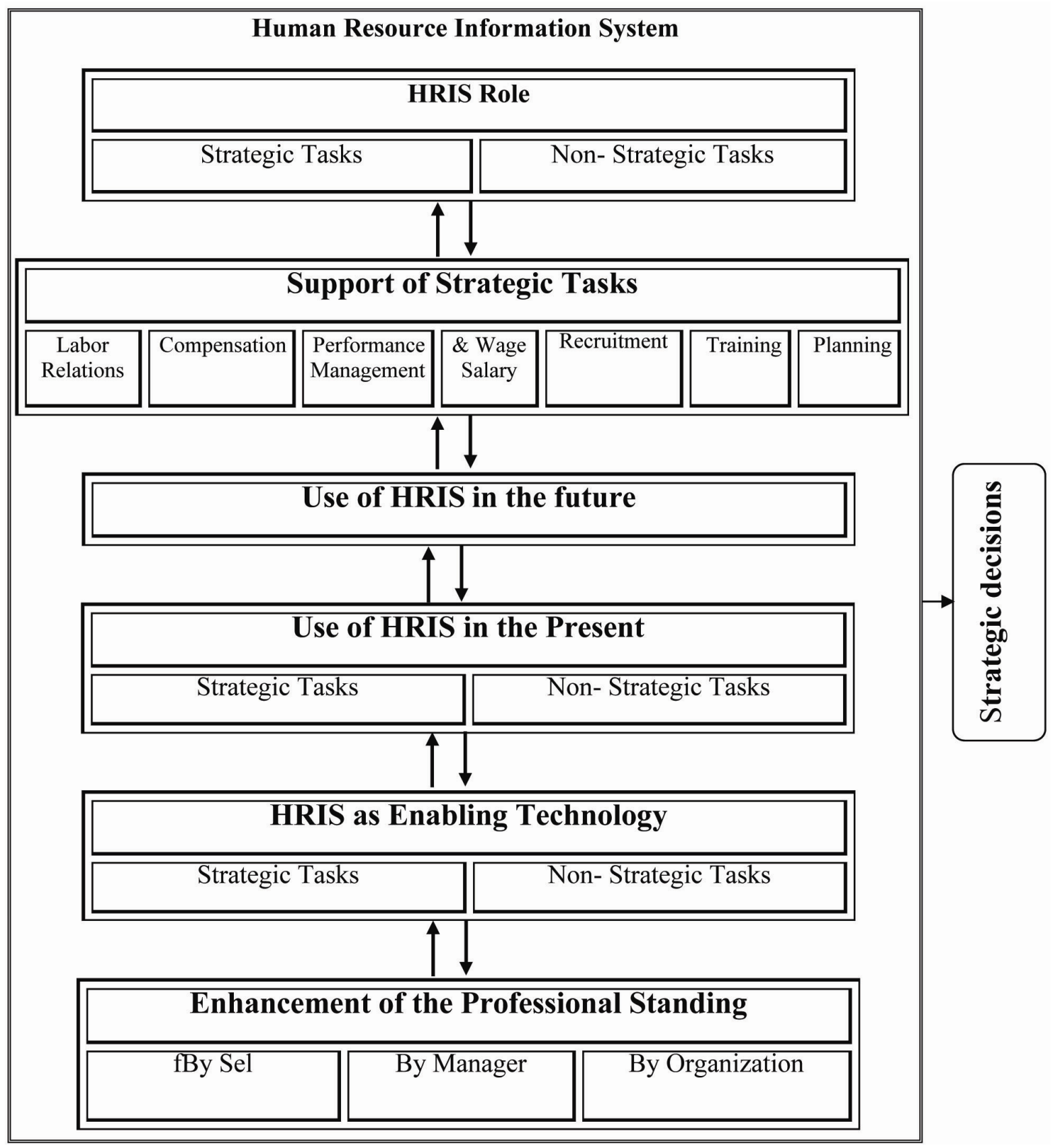

Figure 1. Proposed Research Model 